\title{
Maternal hemoglobin and hematocrit levels during pregnancy and childhood lung function and asthma. The Generation R Study
}

\author{
Sabrina M. C. B. Pereira de Jesus ${ }^{1,2,3} \quad \mid$ Herman T. den Dekker MD ${ }^{1,2,3}$ (iD \\ Johan C. de Jongste MD, PhD ${ }^{2}$ | Irwin K. Reiss ${ }^{4}$ | Eric A. Steegers ${ }^{5}$ | \\ Vincent W. V. Jaddoe MD, PhD ${ }^{1,3,6}$ | Liesbeth Duijts MD, $\mathrm{PhD}^{2,4}$ \\ ${ }^{1}$ The Generation R Study Group, Erasmus MC, University Medical Center Rotterdam, Rotterdam, The Netherlands \\ ${ }^{2}$ Division of Respiratory Medicine, Department of Pediatrics, Erasmus MC, University Medical Center Rotterdam, Rotterdam, The Netherlands \\ ${ }^{3}$ Department of Epidemiology, Erasmus MC, University Medical Center Rotterdam, Rotterdam, The Netherlands \\ ${ }^{4}$ Division of Neonatology, Department of Pediatrics, Erasmus MC, University Medical Center Rotterdam, Rotterdam, The Netherlands \\ ${ }^{5}$ Department of Obstetrics and Gynaecology, Erasmus MC, University Medical Center Rotterdam, Rotterdam, The Netherlands \\ ${ }^{6}$ Department of Pediatrics, Erasmus MC, University Medical Center Rotterdam, Rotterdam, The Netherlands
}

\section{Correspondence}

Dr Liesbeth Duijts, MD, PhD, Erasmus

MC-Sophia Children's Hospital, University Medical Center Rotterdam, Sp-3435, PO Box 2060, Rotterdam 3000 CB, The Netherlands. Email: I.duijts@erasmusmc.nl

\section{Funding information}

The Erasmus Medical Centre, Rotterdam, the Erasmus University Rotterdam; The Netherlands Organization for Health Research and Development, Grant number: VIDI 016.136.361; European Research Council Consolidator, Grant number: ERC-2014-CoG648916; The co-funded programme ERA-Net on Biomarkers for Nutrition and Health (ERA HDHL) (ALPHABET project, Horizon 2020, Grant number: 696295; 2017; ZonMW The Netherlands, Grant number: 529051014; 2017; Science Foundation Ireland, Grant number: SFI/ 16/ERA-HDHL/3360; The European Union; The European Union's Horizon 2020 Research and Innovation Programme, Grant number: 733206

\begin{abstract}
Objective: To examine the associations of maternal hemoglobin and hematocrit levels during pregnancy with childhood lung function and asthma, and whether adverse pregnancy outcomes and atopic predisposition modify the associations.

Methods: In a population-based prospective cohort study among 3672 subjects, we measured maternal hemoglobin and hematocrit levels in early pregnancy, and lung function by spirometry and current asthma by questionnaire at age 10 years.

Results: Higher maternal hematocrit levels, both continuously and categorized into clinical cutoffs, were associated with lower forced expiratory flow at $75 \%$ of forced vital capacity $\left(\mathrm{FEF}_{75}\right)$ in children (Z-score ( $95 \% \mathrm{Cl})$ : $-0.04(-0.07,-0.01)$, per increase of 1 SDS in hematocrit level; Z-score (95\% Cl) difference: $-0.11(-0.20,-0.03)$ compared with normal hematocrit levels, respectively), taking lifestyle and socio-economic factors into account. Adverse pregnancy outcomes and atopic predisposition did not modify the results. No associations of maternal hemoglobin and hematocrit with current asthma were observed.

Conclusion: Higher maternal hematocrit levels during pregnancy are associated with lower childhood lung function but not with risk of asthma. Adverse pregnancy outcomes and atopic predisposition do not modify these associations. Underlying mechanisms need to be further studied.
\end{abstract}

\section{KEYWORDS}

asthma, childhood, hematocrit, hemoglobin, lung function, pregnancy

\section{1 | INTRODUCTION}

Preterm birth and low birth weight are associated with lower lung function and increased risk of asthma in childhood. ${ }^{1-5}$ These associations might be explained by intrauterine mechanisms such as an inadequate oxygen and nutrients supply from mother to the fetus ${ }^{5-7}$ represented by lower or higher maternal hemoglobin and hematocrit status during pregnancy. ${ }^{8-10}$ Lower or higher maternal hemoglobin and hematocrit levels could lead to insufficient oxygen supply to the fetus, ${ }^{11}$ respectively, due to an increased hemodilution, or to an increased blood 
viscosity resulting in an impaired blood flow through the placenta. ${ }^{12}$ Subsequently, insufficient oxygen supply could affect fetal growth and lung development, ${ }^{5,6,13-15}$ and increase the risk of chronic obstructive respiratory diseases in later life. ${ }^{16,17}$

Human cohort studies that examined associations of maternal hemoglobin and hematocrit status with asthma-related outcomes in childhood are scarce, and report inconsistent results. ${ }^{16,17} \mathrm{~A}$ prospective cohort study among 597 children and their mothers showed that maternal anemia based on hemoglobin levels at any time during pregnancy was associated with an increased risk of infant wheezing and childhood asthma. ${ }^{16}$ In contrast, we previously observed no association of maternal hemoglobin levels during pregnancy with wheezing from birth to age 6 years, ever physician-diagnosed asthma, or change in respiratory resistance (Rint) and fractional exhaled nitric oxide (FeNO) at 6 years. ${ }^{17}$ Differences in results of these studies might be explained by differences in type of measurement of hemoglobin or hematocrit levels, definitions of anemia such as hemoglobin level lower than 11 or $10.5 \mathrm{~g} / \mathrm{dL}$, type of lung function measures such as Rint, FeNO, or peak expiratory flow, definitions of asthma such as wheezing, ever or current asthma, ages at time of assessment, or adjustment for confounders. Moreover, the role of socio-economic and lifestyle factors, adverse pregnancy outcomes and atopic predisposition on the association of maternal hemoglobin and hematocrit status during pregnancy with asthma-related outcomes in children is not fully clear. ${ }^{4,18}$

Therefore, we examined the associations of maternal hemoglobin and hematocrit levels during pregnancy with lung function measures and asthma among 3672 children participating in a population-based prospective cohort, and whether these associations were explained by lifestyle and socio-economic factors or modified by adverse pregnancy outcomes and atopic predisposition.

\section{2 | METHODS}

\section{1 | Design}

This study was embedded in the Generation R Study, a prospective population-based cohort study from early fetal life onwards in Rotterdam, the Netherlands. ${ }^{19-21}$ The study was approved by the Medical Ethical Committee of the Erasmus MC, University Medical Centre Rotterdam, the Netherlands. Written informed consent was obtained from all participants. A total of 3672 mothers and their children were included for the current analyses (Fig. 1).

\section{2 | Maternal hemoglobin and hematocrit levels during pregnancy}

As previously described, we assessed maternal serum hemoglobin and hematocrit levels from fresh EDTA plasma samples obtained by maternal venous blood samples at enrolment. ${ }^{15}$ Of all blood samples, $>80 \%$ were obtained before 18 weeks of gestation (median 14.6

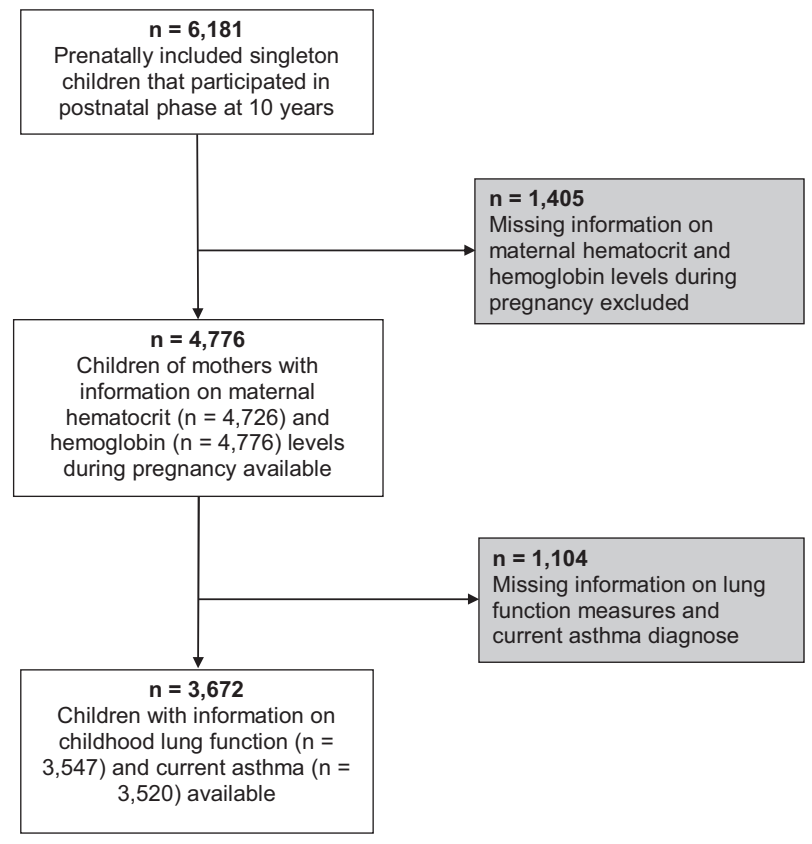

FIGURE 1 Flow chart of participants included for analysis

weeks [5-95\% range: 11.0-22.7 weeks]). Samples were analyzed at STAR Medisch Diagnostisch Centrum (Rotterdam, the Netherlands). ${ }^{19,22}$ Using the World Health Organization (WHO) criteria, ${ }^{23}$ anemia was defined as a serum hemoglobin level $(\mathrm{Hb})$ $<6.83 \mathrm{mmol} / \mathrm{L}$ or hematocrit level $(\mathrm{Ht})<33 \%$, which in our study population reflected the lowest $12.3 \%$. Similarly, elevated serum hemoglobin and hematocrit levels were defined as the upper $12.3 \%$ of the study population resulting in a hemoglobin higher than $8.19 \mathrm{mmol} / \mathrm{L}$ or hematocrit higher than $39 \%$. Normal levels were defined as a serum hemoglobin level between $6.83 \mathrm{mmol} / \mathrm{L}$ and $8.19 \mathrm{mmol} / \mathrm{L}$ or hematocrit level between $33 \%$ and $39 \%$. Standard deviation scores (SDS) were constructed for hemoglobin and hematocrit levels and used as continuous variables in our regression models to obtain a more reliable comparison of the hemoglobin and hematocrit levels within the data from the study population.

\section{3 | Lung function and asthma}

Spirometry was performed according to the American Thoracic Society and European Respiratory Society recommendations ${ }^{24}$ in 9.8-year- (range: 8.6-12.0 years) old children. Lung function measures included forced expiratory volume in $1 \mathrm{~s}\left(\mathrm{FEV}_{1}\right)$, forced vital capacity (FVC), $\mathrm{FEV}_{1} / \mathrm{FVC}$, forced expiratory flow at $25-75 \%$ of $\mathrm{FVC}\left(\mathrm{FEF}_{25-75}\right)$ and forced expiratory flow at $75 \%$ of FVC $\left(\mathrm{FEF}_{75}\right)$, and were converted into sex-, height-, age-, and ethnicity-adjusted Z-scores according to the Global Lung Initiative reference data. ${ }^{25}$ Ever physician-diagnosed asthma, wheezing, and use of inhalant medication in the past 12 months were reported by a parental questionnaire at age 9.8 years, adapted from the International Study on Asthma and Allergy in Childhood (ISAAC). ${ }^{26}$ Current asthma was defined as ever physician diagnosed asthma, with either wheezing or the use of inhalant medication in the past 12 months. 


\section{$2.4 \mid$ Covariates}

Information on maternal characteristics included age, parity, ethnicity, educational level, pre-pregnancy body mass index, smoking during pregnancy, history of asthma and atopy, gestational hypertensive disorders, folic acid supplementation during pregnancy, and alcohol consumption during pregnancy. All data were obtained from questionnaires during pregnancy or from midwife and hospital records at delivery. ${ }^{19}$ Mode of delivery and child's sex, gestational age at birth, and birth weight were obtained from midwife and hospital records at birth.

\section{5 | Statistical analysis}

Independent $T$-test and chi-square test were used to compare all characteristics of our population under study with those with missing information on maternal hemoglobin and hematocrit levels during pregnancy or those with missing information of lung function measures and current asthma. For association analyses, we examined the associations of maternal hemoglobin and hematocrit levels during pregnancy with childhood lung function measures and asthma using linear and logistic regression analysis. First, this model was adjusted for gestational age at which maternal blood sampling occurred (crude model). ${ }^{15}$ Second, we additionally adjusted for socio-economic factors such as maternal age, parity, educational level, and pre-pregnancy BMI (model 1), and lifestyle factors such as folic acid supplementation and alcohol consumption during pregnancy (model 2). Third, we adjusted for all socio-economic and lifestyle factors (full model). Confounders were selected based on literature, if they were associated with hemoglobin and hematocrit levels and with lung function or asthma, or if the effect estimate of the crude analyses changed $\geq 10 \%$ when we additionally adjusted for the confounder. Missing data in covariates were imputed by the multiple imputation method using chained equations to select the most likely value for a missing response. ${ }^{27}$ When data are missing not at random, bias in analysis based on multiple imputation may be as large or larger than bias in analysis of complete cases Missing data of covariates were imputed to reduce bias and improve efficiency. Multiple imputation analysis aim to avoid bias only if enough variables predictive of missing values are included in the imputation model. ${ }^{28}$ Therefore, we included variables used in the multivariate models, and additionally important variables that could correctly predict the missing values including socio-economic factors (family income, paternal education level, maternal ethnicity, and child day care attendance in the first year of life) and biological factors (maternal smoking, atopy and asthma family history, mode of delivery, gestational age at birth, breastfeeding, and maternal weight and height at enrolment). Non-linear associations were tested by adding the quadratic term for hemoglobin and hematocrit levels in the models. We used similar regression analyses for the associations of low and elevated hemoglobin and hematocrit levels with lung function measures and current asthma, using normal hemoglobin and hematocrit levels as reference categories. Last, effect modification due to adverse pregnancy outcomes (caesarian section, lower gestational age, or weight at birth), and atopic predisposition factors (maternal history of asthma or atopy and child's allergic sensitization) were examined in the fully adjusted models by adding the product term between the determinant and the covariate in the statistical models. We used the F-statistic to test the model fit of models with and without interaction terms. $P$ values for F-statistics $<0.05$ were considered significant, indicating a different model fit when comparing the models with and without interaction terms. All measures of association are presented with their $95 \%$ Confidence Intervals $(95 \% \mathrm{Cl})$. Statistical analyses were performed using SPSS version 21.0 for Windows software (SPSS Inc, Chicago, IL).

\section{3 | RESULTS}

Maternal and child characteristics are presented in Table 1. Mean maternal hemoglobin and hematocrit levels were $7.56 \mathrm{mmol} / \mathrm{L}$ $(S D \pm 0.61)$ and $36 \%(S D \pm 3.00)$, respectively. Based on hemoglobin and hematocrit levels, respectively, $12.2 \%$ and $17.5 \%$ of the mothers were anemic, and $15 \%$ and $16.8 \%$ had elevated $\mathrm{Hb}$ or $\mathrm{Ht}$ levels. Mean absolute values for FEV 1 , FVC, $\mathrm{FEV}_{1} / \mathrm{FVC}, \mathrm{FEF}_{25-75}$, and $\mathrm{FEF}_{75}$ of the children were 2.02 L (SD \pm 0.30 ), 2.33 L (SD \pm 0.36 ), 0.87 ( $S D \pm 0.06$ ), $2.71 \mathrm{~L} / \mathrm{s}(\mathrm{SD} \pm 0.64)$, and $1.14 \mathrm{~L} / \mathrm{s}(\mathrm{SD} \pm 0.34)$, respectively. Current asthma was observed in $7.2 \%$ of the participants. Compared with those included in our study, we observed that mothers not included in the study were younger, more often multiparous, had a higher prepregnancy BMI, more often had gestational hypertensive disorders, less often used folic acid supplementation and alcohol during pregnancy, more often had caesarean-section as mode of delivery of their child, and that children were born at an earlier gestational age ( $P$ values $<0.01$ ) (Table S1).

\section{1 | Hemoglobin and hematocrit levels and respiratory outcomes}

The crude model showed that higher maternal hemoglobin levels were associated with lower $\mathrm{FEF}_{25-75}$ and $\mathrm{FEF}_{75}$ in children (Z-score [95\% Cl]: $-0.05[-0.09,-0.01]$ and $-0.05[-0.08,-0.02]$, respectively, per increase of 1 SDS in hemoglobin level), and that higher maternal hematocrit levels were associated with lower FEV 1 /FVC and $\mathrm{FEF}_{75}$ in children $(-0.04$ [-0.07, -0.01] and -0.05 [-0.08, -0.02], respectively, per increase of 1 SDS in hematocrit level) (Table 2). Maternal hemoglobin and hematocrit levels were not associated with $\mathrm{FEV}_{1}, \mathrm{FVC}$ or current asthma. The effect estimates of associations of maternal hemoglobin with $\mathrm{FEF}_{25-75}$ and $\mathrm{FEF}_{75}$, and of associations of maternal hematocrit level with $\mathrm{FEV}_{1} / \mathrm{FVC}$ attenuated into significant when socio-economic (model 1) and lifestyle factors (model 2), respectively, were taken into account. After adjusting for both socio-economic and lifestyle factors (full model), only the association of a higher maternal hematocrit level during pregnancy with a lower childhood $\mathrm{FEF}_{75}$ remained $(-0.04$ [-0.07, -0.01], per increase of 1 SDS in hematocrit level). Based on hemoglobin clinical cut-offs, maternal anemia during pregnancy was associated with a high $\mathrm{FEF}_{25-75}$ (difference in Z-score [95\% Cl]: 0.16 $[0.05,0.27]$ ) when compared to normal hemoglobin levels (Fig. 2D, Table S2). Based on hematocrit clinical cut-offs, an elevated 
TABLE 1 Characteristics of mothers and their children $(n=3672)$

\begin{tabular}{|c|c|c|}
\hline & Original data & $\begin{array}{l}\text { Imputed } \\
\text { data }\end{array}$ \\
\hline \multicolumn{3}{|l|}{ Maternal characteristics } \\
\hline Age (years) & $30.9(4.84)$ & $30.9(4.84)$ \\
\hline \multicolumn{3}{|l|}{ Parity (\%) } \\
\hline Nullipara & $58.4(2131)$ & $58.4(2145)$ \\
\hline Multipara & $41.6(1518)$ & $41.6(1527)$ \\
\hline Missing & $0.6(23)$ & \\
\hline \multicolumn{3}{|l|}{ Ethnicity (\%) } \\
\hline European & $65.2(2346)$ & $64.6(2373)$ \\
\hline Non-European & $34.8(1254)$ & $35.4(1299)$ \\
\hline Missing & $2.0(72)$ & \\
\hline \multicolumn{3}{|l|}{ Education level (\%) } \\
\hline Less than secondary level & $48.8(1702)$ & $49.9(1832)$ \\
\hline Higher & $51.2(1786)$ & $50.1(1840)$ \\
\hline Missing & $5.0(184)$ & \\
\hline $\begin{array}{l}\text { Prepregnancy body mass index } \\
\left(\mathrm{kg} / \mathrm{m}^{2}\right)\end{array}$ & $24.54(4.23)$ & $24.54(4.23)$ \\
\hline \multicolumn{3}{|l|}{ Smoking during pregnancy (\%) } \\
\hline No & $76.2(2513)$ & $76.2(2797)$ \\
\hline Yes & $23.8(786)$ & $23.8(875)$ \\
\hline Missing & $5.0(184)$ & \\
\hline \multicolumn{3}{|l|}{ History of asthma or atopy (\%) } \\
\hline No & $62.3(2014)$ & - \\
\hline Yes & $37.7(1220)$ & - \\
\hline Missing & $11.9(438)$ & - \\
\hline \multicolumn{3}{|c|}{ Gestational hypertensive disorders (\%) } \\
\hline No & $96.3(3366)$ & $96.0(3525)$ \\
\hline Yes & $3.7(130)$ & $4.0(147)$ \\
\hline Missing & $4.8(176)$ & \\
\hline \multicolumn{3}{|l|}{ Folic acid supplementation (\%) } \\
\hline No & $21.7(621)$ & $23.3(856)$ \\
\hline Start 1 st 10 weeks of gestation & 30.8 (879) & $31.2(1145)$ \\
\hline Start periconceptional & $47.5(1357)$ & $45.5(1671)$ \\
\hline Missing & $22.2(815)$ & \\
\hline \multicolumn{3}{|c|}{ Alcohol consumption during pregnancy (\%) } \\
\hline None & $42.6(1390)$ & $43.0(1580)$ \\
\hline Any & $57.4(1872)$ & $57.0(2091)$ \\
\hline Missing & $11.2(410)$ & \\
\hline \multicolumn{3}{|l|}{ Mode of delivery (\%) } \\
\hline Vaginal & $88.1(2941)$ & $88.2(3239)$ \\
\hline Caeserean-section & $11.9(396)$ & $11.8(433)$ \\
\hline Missing & $9.1(335)$ & \\
\hline Hemoglobin (mmol/L) & $7.56(0.61)$ & - \\
\hline \multicolumn{3}{|l|}{ Hemoglobin clinical categories (\%) } \\
\hline Anemia (<6.83 mmol/L) & $12.0(442)$ & - \\
\hline Normal (6.83-8.20 mmol/L) & $72.8(2672)$ & - \\
\hline $\begin{array}{l}\text { Elevated hemoglobin } \\
\qquad>8.20 \mathrm{mmol} / \mathrm{L})\end{array}$ & $15.2(558)$ & - \\
\hline
\end{tabular}

(Continues)
TABLE 1 (Continued)

\begin{tabular}{|lll}
\hline & Original data & $\begin{array}{l}\text { Imputed } \\
\text { data }\end{array}$ \\
\hline Hematocrit & $0.36(0.03)$ & - \\
\hline Hematocrit clinical categories (\%) & & \\
\hline Anemia (<33\%) & $17.6(640)$ & - \\
\hline Normal (33-39\%) & $65.4(2376)$ & - \\
\hline Elevated hematocrit (>39\%) & $16.9(615)$ & - \\
\hline Child's characteristics & & \\
\hline Female sex (\%) & $51.7(1900)$ & $51.7(1900)$ \\
\hline Gestational age at birth & $39.94(1.71)$ & $39.94(1.71)$ \\
\hline (weeks) & & \\
\hline Birth weight (grams) & 3442.39 & 3441.57 \\
\hline Breastfeeding (\%) & $(541.91)$ & $(543.2)$ \\
\hline No & & \\
\hline Yes & $6.9(209)$ & $7.3(267)$ \\
\hline Missing & $93.1(2816)$ & $92.7(3405)$ \\
\hline Age & $17.6(647)$ & \\
\hline FEV1 & $9.79(0.34)$ & $9.79(0.34)$ \\
\hline FVC & $2.02(0.30)$ & - \\
\hline FEV1/FVC & $18.3(672)$ & - \\
\hline FEF25-75 & $2.33(0.36)$ & - \\
\hline FEF75 & $0.87(0.06)$ & - \\
\hline Current asthma & $2.71(0.64)$ & - \\
\hline No & $1.14(0.34)$ & - \\
\hline Yes & & \\
\hline Missing & $92.7(2781)$ & - \\
\hline & & \\
\hline
\end{tabular}

Values are means (SD) or valid percentages (absolute numbers).

maternal hematocrit level during pregnancy was associated with a low $\mathrm{FEF}_{75}$ (difference in Z-score [95\%Cl]: -0.11 [-0.20, -0.03]) when compared to normal hematocrit levels (Fig. 2E, Table S2). Maternal anemia or elevated hemoglobin or hematocrit levels were not associated with $\mathrm{FEV}_{1}, \mathrm{FVC}, \mathrm{FEV}_{1} / \mathrm{FVC}$, or current asthma in children (Fig. 2A-C, Table S2).

We did not observe any non-linear associations of maternal hemoglobin and hematocrit levels with childhood lung function or asthma (data not shown, $P$ values for quadratic term $>0.05$ ). We did not observe modifying effects of maternal mode of delivery, child's gestational age and weight at birth, maternal history of asthma or atopy and child's allergic sensitization for the associations of maternal hemoglobin or hematocrit level with childhood lung function measures or current asthma $(P$ values for interaction $>0.05, P$ values for F-statistics $>0.05$ ) .

\section{4 | DISCUSSION}

In this population-based prospective birth cohort study, we observed that higher maternal hematocrit levels during pregnancy, both continuously and categorized according to clinical cut-offs, were associated with 
TABLE 2 Associations of maternal hemoglobin and hematocrit levels with childhood lung function measures and asthma

\begin{tabular}{|c|c|c|c|c|c|c|}
\hline & $\begin{array}{l}\text { FEV }_{1} \\
\text { Z-score }(95 \% \mathrm{Cl})\end{array}$ & $\begin{array}{l}\text { FVC } \\
\text { Z-score }(95 \% \mathrm{Cl})\end{array}$ & $\begin{array}{l}\mathrm{FEV}_{1} / \mathrm{FVC} \\
\text { Z-score }(95 \% \mathrm{Cl})\end{array}$ & $\begin{array}{l}\text { FEF }_{25-75} \\
\text { Z-score }(95 \% \mathrm{Cl})\end{array}$ & $\begin{array}{l}\mathrm{FEF}_{75} \\
\text { Z-score }(95 \% \mathrm{Cl})\end{array}$ & $\begin{array}{l}\text { Current asthma } \\
\text { OR }(95 \% \mathrm{Cl})\end{array}$ \\
\hline \multicolumn{7}{|c|}{ Hemoglobin (SDS) } \\
\hline Model $1^{\mathrm{b}}$ & $-0.02(-0.06,0.02)$ & $-0.01(-0.05,0.02)$ & $-0.02(-0.06,0.01)$ & $-0.05(-0.09,-0.01)^{*}$ & $-0.04(-0.07,-0.01)^{*}$ & $1.01(0.86,1.18)$ \\
\hline Model $2^{c}$ & $-0.01(-0.04,0.03)$ & $0.00(-0.03,0.04)$ & $-0.02(-0.06,0.01)$ & $-0.04(-0.08,0.00)$ & $-0.03(-0.06,0.00)$ & $1.02(0.87,1.19)$ \\
\hline \multicolumn{7}{|c|}{ Hematocrit (SDS) } \\
\hline Crude $^{a}$ & $-0.02(-0.05,0.02)$ & $0.00(-0.03,0.03)$ & $-0.04(-0.07,-0.01)^{*}$ & $-0.04(-0.07,0.00)$ & $-0.05(-0.08,-0.02)^{* *}$ & $1.01(0.87,1.17)$ \\
\hline Model $1^{\mathrm{b}}$ & $-0.02(-0.06,0.01)$ & $-0.01(-0.04,0.02)$ & $-0.03(-0.07,0.00)$ & $-0.03(-0.07,0.01)$ & $-0.05(-0.08,-0.02)^{* *}$ & $1.01(0.87,1.17)$ \\
\hline Model $2^{c}$ & $-0.01(-0.04,0.03)$ & $0.01(-0.03,0.04)$ & $-0.03(-0.07,0.00)$ & $-0.02(-0.06,0.01)$ & $-0.04(-0.07,-0.01)^{*}$ & $1.02(0.83,1.19)$ \\
\hline
\end{tabular}

Values reflect changes in Z-scores or odds ratios (OR) with their $95 \%$ Confidence Interval per increase of one SDS hemoglobin or hematocrit * $P$-value $<0.05$, ${ }^{* *} P$-value $<0.01$.

${ }^{a}$ Adjusted for gestational age at maternal blood sampling.

${ }^{b}$ Crude model additionally adjusted for maternal age, parity, educational level, pre-pregnancy BMI.

${ }^{\mathrm{c} C}$ Crude model additionally adjusted for maternal folic acid supplementation and alcohol consumption during pregnancy.

${ }^{\mathrm{d}}$ Adjusted for all confounders.

lower $\mathrm{FEF}_{75}$ in children taking lifestyle and socio-economic factors into account. Maternal anemia during pregnancy based on hemoglobin levels was associated with a high $\mathrm{FEF}_{25-75}$, compared to normal hemoglobin levels. Results were not modified by adverse pregnancy outcomes and atopic predisposition. We did not observe any associations of maternal hemoglobin and hematocrit levels with current asthma, although residual confounders might affect our findings.

\section{1 | Comparison with previous studies}

Prospective cohort studies that assessed the association of maternal hemoglobin or hematocrit levels with childhood lung function and asthma are scarce, ${ }^{16,17}$ and show inconsistent results. We aimed to address all factors that explained differences in results of the previous studies into account, and now used both hemoglobin and hematocrit levels, WHO clinical cut-off definitions, lung function measured by spirometry, which is an objective and reliable ${ }^{29,30}$ method, took gestational age at blood sampling and multiple confounders into account, and explored intermediating and effect modifying factors. We observed associations of maternal hemoglobin and hematocrit levels measured in early pregnancy with lower childhood lung function, but not with asthma at age 10 years. A population based cohort study among 597 children and their mothers observed associations of maternal anemia in late pregnancy with wheezing and asthma until age 6 years, however we did not. Main differences between the studies that could explain the different findings are the period during pregnancy at which hemoglobin and hematocrit blood levels were measured, in the first pregnancy versus at delivery, the adjustment for gestational age at blood sampling or not, and the determinants definitions. Previous studies have shown that hemoglobin or hematocrit levels might change according to the pregnancy trimester evaluated ${ }^{23}$ and that mothers are more likely to develop anemia in the third trimester. ${ }^{31}$ Period in pregnancy at which maternal anemia is measured seems therefore important. Also, the age at which asthma was measured, and differences in study populations, a high-risk asthma population versus a populationbased cohort, might have influenced differences in results.

Maternal iron status during pregnancy may be used as proxy of the overall maternal nutritional status and also as a proxy of maternal anemia, since iron deficiency is a very common cause of anemia. ${ }^{8} \mathrm{~A}$ previous study that examined the association of iron levels during pregnancy with asthma-related outcomes in children ${ }^{32}$ suggested that lower maternal iron levels during pregnancy are associated with increased risks of wheezing and atopic sensitization in children whereas higher maternal iron levels during pregnancy are related to better lung function measures. Therefore, future studies need to focus on maternal hemoglobin and hematocrit in combination with iron levels status during multiple trimesters of pregnancy and the association with childhood lung function and asthma.

\section{2 | Interpretation of results}

The associations of maternal hemoglobin and hematocrit levels during pregnancy with childhood lung function might be explained by the importance of adequate oxygen and nutrients supply from the mother to the fetus in order to guarantee an adequate general and lung growth and development. ${ }^{5-7}$ Low maternal hemoglobin levels may represent an insufficient oxygen supply to the fetus since the hemoglobin molecule is the oxygen carrier in our body. ${ }^{33}$ High hemoglobin or hematocrit levels during pregnancy may lead to an important increase in the blood viscosity inducing an impaired blood flow through the placenta and, therefore, an insufficient oxygen supply to the fetus. Animal models have shown that undernutrition and hypoxia lead to an impaired lung development. $^{34,35}$ In sheep, it has been shown that intrauterine exposure to hypoxia may inhibit lung growth and DNA synthesis. ${ }^{34} \mathrm{~A}$ study in lambs fetuses showed that hypoxemia decreases pulmonary blood flow, which might lead to reduced oxygen and nutrients supply that could have an adverse impact on lung development. ${ }^{35}$ 
(A)

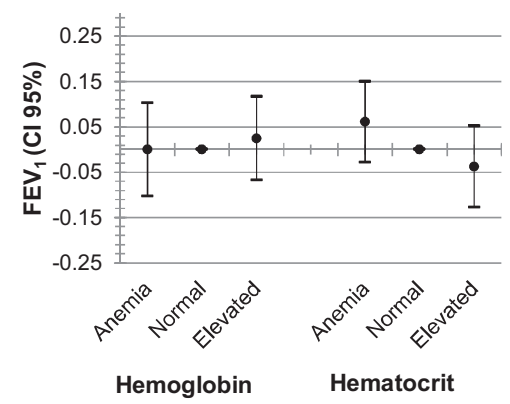

(D)

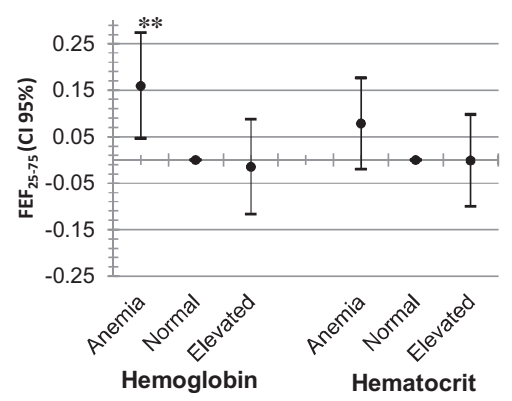

(B)

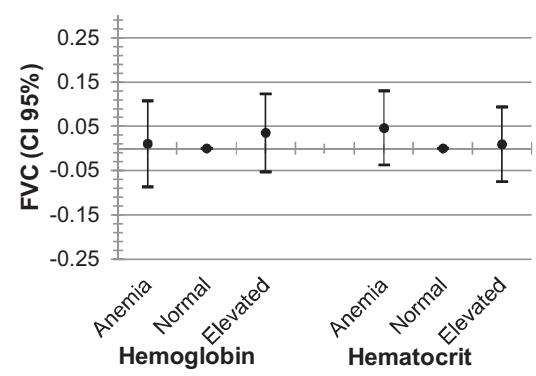

(E)

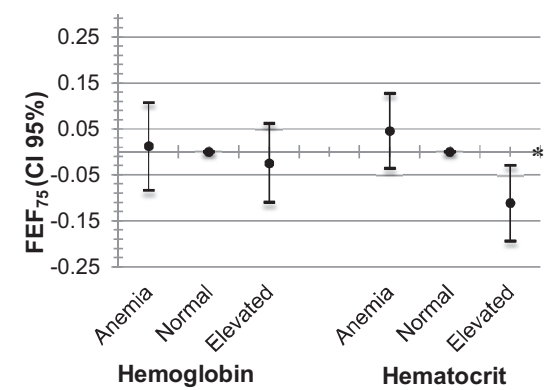

(C)

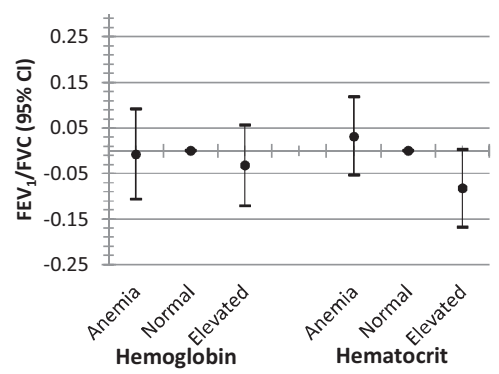

(F)

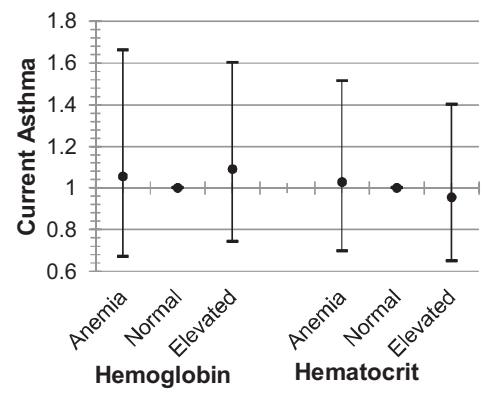

FIGURE 2 Associations of clinical cut-offs of maternal hemoglobin and hematocrit levels with childhood FEV 1 (A), FVC (B), FEV 1 /FVC (C), $\mathrm{FEF}_{25-75}(\mathrm{D}), \mathrm{FEF}_{75}(\mathrm{E})$, and current asthma (F). Values reflect changes in Z-scores or odds ratios (OR) with their 95\% Confidence Interval. Reference group are those mothers with a normal hemoglobin or hematocrit level. Models are adjusted for gestational age at maternal blood sampling, maternal age, parity, educational level, pre-pregnancy BMI, folic acid supplementation, and alcohol consumption during pregnancy. ${ }^{*} P$-value $<0.05,{ }^{* *} P$-value $<0.01$

It has been suggested that in some circumstances the physiological plasma-volume expansion that usually occur in pregnancy may fail which could lead to relatively elevated hemoglobin or hematocrit levels during pregnancy. ${ }^{36,37}$ This would imply more viscous blood and could potentially lead to impaired placental perfusion and inappropriate blood and nutrients supply to the fetus. Our study showed that maternal elevated hematocrit levels were associated with lower lung function measures and might support the proposed hypothesis that maternal blood hyper viscosity during pregnancy influences fetal growth and lung development and later life lower lung function.

We observed that maternal anemia was associated with a high $\mathrm{FEF}_{25-75}$ in children. We analyzed hemoglobin and hematocrit levels mostly from blood samples obtained in the first trimester of pregnancy but hemoglobin or hematocrit levels might change according to the pregnancy trimester evaluated. ${ }^{23}$ During early pregnancy, the mother is exposed to normal hemodynamic changes with an increase in the blood plasma disproportionally greater than increase of blood red cells numbers, which results in a physiologic anemia. Cohort studies have suggested that maternal physiologic anemia and iron deficiency anemia, which more often occurs in the third trimester, ${ }^{31}$ might have different consequences to child health. ${ }^{9,10,32}$ Iron deficiency seems associated with adverse child health outcomes while physiologic anemia seems to be associated with better outcomes for mother and child. Our results are in line with this hypothesis, although we were unable to assess the role of maternal iron status during pregnancy on lung function and asthma in children. It has also been suggested that the placenta might adapt to lower levels of hemoglobin or hematocrit leading to an increase in its vascular density. ${ }^{11}$ This adaptive response could enhance fetal development, and our findings of maternal anemia leading to a high $\mathrm{FEF}_{25-75}$ could be attributed to this mechanism.

\subsection{Strengths and limitations}

We used a population-based prospective cohort design from early pregnancy onwards, with detailed information on maternal and child characteristics and on maternal red blood status. Spirometry is the preferred method to assess lung function, ${ }^{29,30,38}$ and to date this is the first study that uses this method as asthma-related outcome with maternal hemoglobin and hematocrit levels during pregnancy and long-term pulmonary outcomes under study. However, some limitations do apply. First, subjects lost to follow-up had less favorable social-economic status and lifestyle characteristics than those included in our study. This could have led to selection bias if the associations of maternal hemoglobin and hematocrit levels during pregnancy with childhood lung function and asthma would have been different between those subjects included and those lost to follow-up. This seems unlikely, but needs to be considered. Additionally, we did not observe any differences between complete case analysis and multiple imputation, which suggests that any non-random missing data did not affect our results. ${ }^{28}$ Second, we used self-reported data to define current asthma in our study population. Although we used 
questions previously validated in other cohorts studies and commonly used in epidemiological studies, we cannot exclude the possibility of under- or over-reporting, which could have led to misclassification of the asthma outcome and, thus, to under- or over-estimations of the true associations. Third, although we have included many potential confounders in our analysis, it is possible that residual confounding such as nutritional factors remains an issue in our study. Last, we observed most consistent associations of maternal hematocrit levels with $\mathrm{FEF}_{75}$ but not with other lung function measures or current asthma. It has been shown that $\mathrm{FEF}_{75}$ correlates more closely to mild or moderate asthma whereas $\mathrm{FEV}_{1}$ with more severe asthma cases. ${ }^{38}$ Therefore, in our population-based study, we might have had a higher prevalence of mild and moderate asthma, reflected by $\mathrm{FEF}_{75}$, than severe asthma cases, which has consequences for the generalizability of our results. Furthermore, our current asthma definition did not include spirometry values, which might have been normal due to treatment. Also, current asthma was measured subjectively by parental reports while lung function objectively by spirometry, which might partly explain the absence of associations of maternal hemoglobin and hematocrit levels with asthma diagnose itself.

In conclusion, our study suggests that higher maternal hematocrit levels are associated with lower lung function, and maternal anemia in early pregnancy with higher lung function in childhood. Results are partly explained by lifestyle and socio-economic factors, and not modified by adverse pregnancy outcomes or atopic predisposition. Future studies are needed to explore whether maternal hemoglobin or hematocrit levels during pregnancy are associated with lung function and asthma in later life, and to explore potential underlying nutritional factors.

\section{ACKNOWLEDGMENTS}

The Generation R Study is conducted by the Erasmus Medical Centre in close collaboration with the School of Law and the Faculty of Social Sciences at the Erasmus University, Rotterdam, the Municipal Health Service, Rotterdam area, and the Stichting Trombosedienst and Artsenlaboratorium Rijnmond (Star-MDC), Rotterdam. We gratefully acknowledge the contribution of the children and their parents, general practitioners, hospitals, midwives, and pharmacies in Rotterdam. The Generation R Study is made possible by financial support from the Erasmus Medical Centre, Rotterdam, the Erasmus University Rotterdam and the Netherlands Organization for Health Research and Development. $\mathrm{Dr}$ Vincent Jaddoe received an additional grant from the Netherlands Organization for Health Research and Development (VIDI 016.136.361) and an European Research Council Consolidator Grant (ERC-2014-CoG-648916). Dr Liesbeth Duijts received funding from the co-funded programme ERA-Net on Biomarkers for Nutrition and Health (ERA HDHL) (ALPHABET project, Horizon 2020 (grant agreement no 696295; 2017), ZonMW The Netherlands (no 529051014; 2017), Science Foundation Ireland (no SFI/16/ERA-HDHL/3360), and the European Union). The project received funding from the European Union's Horizon 2020 research and innovation programme under grant agreement No 733206 (LIFECYCLE). The researchers are independent from the funders. The study sponsors had no role in the study design, data analysis, interpretation of data, or writing of this report. The researchers are independent from the funders. The study sponsors had no role in the study design, data analysis, interpretation of data, or writing of this report.

\section{CONFLICT OF INTEREST}

None.

\section{AUTHORS' CONTRIBUTION}

SPJ, HD, LD contributed to the conception and design, acquisition of data, analyses and interpretation of the data, drafted the article, revised it critically for important intellectual content, and gave final approval of the version to be published. JJ, IR, ES, VJ contributed to the conception and design, acquisition of data, revised the drafted manuscript critically for important intellectual content, and gave final approval of the version to be published.

\section{REFERENCES}

1. Duijts L. Fetal and infant origins of asthma. Eur J Epidemiol. 2012;27:5-14.

2. Duijts L, Reiss IK, Brusselle G, de Jongeste JC. Early origins of chronic obstructive lung diseases across the life course. Eur J Epidemiol. 2014;29:871-885.

3. Maritz GS, Morley CJ, Harding R. Early developmental origins of impaired lung structure and function. Early Hum Dev. 2005;81:763-771.

4. den Dekker HT, Sonneschein-van der Voort AMM, de Jongest JC, et al. Early growth characteristics and the risk of reduced lung function and asthma: a meta-analysis of 25,000 children. J Allergy Clin Immunol. 2016;137:1026-1035.

5. Harding R, Maritz G. Maternal and fetal origins of lung disease in adulthood. Semin Fetal Neonatal Med. 2012;17:67-72.

6. Briana DD, Malamitsi-Puchner A. Small for gestational age birth weight: impact on lung structure and function. Paediatr Respir Rev. 2013;14:256-262.

7. Henderson AJ, Warner JO. Fetal origins of asthma. Semin Fetal Neonatal Med. 2012;17:82-91.

8. Yip R. Significance of an abnormally low or high hemoglobin concentration during pregnancy: special consideration of iron nutrition. Am J Clin Nutr. 2000;72:272S-279S.

9. Welten M, Gaillard R, Hofman A, de Jonge LL, Jaddoe VW. Maternal haemoglobin levels and cardio-metabolic risk factors in childhood: the Generation R study. BJOG. 2015;122:805-815.

10. Steer $P$, Alam MA, Wadsworth J, Welch A. Relation between maternal haemoglobin concentration and birth weight in different ethnic groups. BMJ. 1995;310:489-491.

11. Stangret A, Wnuk A, Szewczyk G, Pyzlak M, Szukiewicz D. Maternal hemoglobin concentration and hematocrit values may affect fetus development by influencing placental angiogenesis. J Matern Fetal Neonatal Med. 2016;30:199-204.

12. Steer PJ. Maternal hemoglobin concentration and birth weight. Am J Clin Nutr. 2000;71:1285S-1287S

13. Cordina M, Bhatti S, Fernandez M, Syngelaki A, Nicolaides KH, Kametas NA. Maternal hemoglobin at 27-29 weeks' gestation and severity of pre-eclampsia. J Matern Fetal Neonatal Med. 2015;28:1575-1580. 
14. Koura GK, Ouedraogo S, Le Port A, et al. Anaemia during pregnancy: impact on birth outcome and infant haemoglobin level during the first 18 months of life. Trop Med Int Health. 2012;17:283-291.

15. Gaillard R, Ellers PH, Yassine S, Hofman A, Steegers EA, Jaddoe VW. Risk factors and consequences of maternal anaemia and elevated haemoglobin levels during pregnancy: a population-based prospective cohort study. Paediatr Perinat Epidemiol. 2014;28:213-226.

16. Triche EW, Lindesberg LS, Wickner PG, Belanger K, Leaderer BP, Bracken MB. Association of maternal anemia with increased wheeze and asthma in children. Ann Allergy Asthma Immunol. 2011;106:131-139 e1.

17. Tromp II, Gaillard R, Kieft-de Jong JC, et al. Maternal hemoglobin levels during pregnancy and asthma in childhood: the Generation R Study. Ann Allergy Asthma Immunol. 2014;112:263-265.

18. Sonnenschein van der Voort AM, Arends LR, de Jongest JC, et al. Preterm birth, infant weight gain, and childhood asthma risk: a metaanalysis of 147,000 European children. J Allergy Clin Immunol. 2014;133:1317-1329.

19. Jaddoe VW, van Duijn CM, Franco OH, et al. The Generation R Study: design and cohort update 2012. Eur J Epidemiol. 2012;27:739-756.

20. Kruithof CJ, Kooijman MN, van Duijn CM, et al. The Generation R Study: biobank update 2015. Eur J Epidemiol. 2014;29:911-927.

21. Kooijman MN, Kruithof CJ, van Duijn CM, et al. The Generation R Study: design and cohort update 2017. Eur J Epidemiol. 2016;31: 1243-1264.

22. Jaddoe VW, Bakker R, van Duijn CM, et al. The Generation R Study Biobank: a resource for epidemiological studies in children and their parents. Eur J Epidemiol. 2007;22:917-923.

23. WHO, Hemoglobin concentrations for the diagnosis of anaemia and assessment of severity. Vitamin and Mineral Nutrition Information System. Geneva, Switzerland: World Health Organization, 2011.

24. Miller MR, Hankinson J, Brusasco V, et al. Standardisation of spirometry. Eur Respir J. 2005;26:319-338.

25. Quanjer $\mathrm{PH}$, Stanojevic $\mathrm{S}$, Cole TJ, et al. Multi-ethnic reference values for spirometry for the 3-95-yr age range: the global lung function 2012 equations. Eur Respir J. 2012;40:1324-1343.

26. Asher MI, Keil U, Anderson HR, et al. International study of asthma and allergies in childhood (ISAAC): rationale and methods. Eur Respir J. 1995;8:483-491.

27. Azur MJ, Stuart EA, Frangakis C, Leaf PJ. Multiple imputation by chained equations: what is it and how does it work?. Int J Methods Psychiatr Res. 2011;20:40-49.

28. Sterne JA, White IR, Carlin JB, et al. Multiple imputation for missing data in epidemiological and clinical research: potential and pitfalls. BMJ. 2009;338:b2393.
29. Beydon N, Mahut B, Maingot L, et al. Baseline and post-bronchodilator interrupter resistance and spirometry in asthmatic children. Pediatr Pulmonol. 2012;47:987-993.

30. Boccaccino A, Peroni DG, Pietrobelli A, et al. Assessment of variable obstruction by forced expiratory volume in 1 second, forced oscillometry, and interrupter technique. Allergy Asthma Proc. 2007;28:331-335.

31. Lee Al, Okam MM. Anemia in pregnancy. Hematol Oncol Clin North Am. 2011;25:241-259, vii.

32. Nwaru $\mathrm{Bl}$, Hayes $\mathrm{H}$, Gambling L, et al. An exploratory study of the associations between maternal iron status in pregnancy and childhood wheeze and atopy. Br J Nutr. 2014;112:2018-2027.

33. Adamson JW, Finch CA. Hemoglobin function, oxygen affinity, and erythropoietin. Annu Rev Physiol. 1975;37:351-369.

34. Hooper SB, Bocking AD, White S, Challis JR, Han VK. DNA synthesis is reduced in selected fetal tissues during prolonged hypoxemia. Am $J$ Physiol. 1991;261:R508-R514.

35. Abman SH, Accurso FJ, Wilkening RB, Meschia G. Persistent fetal pulmonary hypoperfusion after acute hypoxia. Am J Physiol. 1987;253:H941-H948.

36. Little MP, Brocard P, Elliott P, Steer PJ. Hemoglobin concentration in pregnancy and perinatal mortality: a London-based cohort study. Am J Obstet Gynecol. 2005;193:220-226.

37. Murphy JF, O'Riordan J, Newcombe RG, Coles EC, Pearson JF. Relation of haemoglobin levels in first and second trimesters to outcome of pregnancy. Lancet. 1986;1:992-995.

38. Francisco B, Ner Z, Ge B, Hewett J, Konig P. Sensitivity of different spirometric tests for detecting airway obstruction in childhood asthma. J Asthma. 2015;52:505-511.

\section{SUPPORTING INFORMATION}

Additional Supporting Information may be found online in the supporting information tab for this article.

How to cite this article: Pereira de Jesus SMCB, den Dekker $\mathrm{HT}$, de Jongste JC, et al. Maternal hemoglobin and hematocrit levels during pregnancy and childhood lung function and asthma. The Generation R Study. Pediatric Pulmonology. 2018;53:130-137. https://doi.org/10.1002/ppul.23733 